\title{
Comparison of Aerobic Performance Testing Protocols in Elite Male Wheelchair Basketball Players
}

\author{
by \\ Bartosz Molik ${ }^{1}$,Andrzej Kosmol', Natalia Morgulec-Adamowicz', \\ Judit Lencse-Mucha ${ }^{1}$, Anna Mrózz ${ }^{2}$ Karol Gryko², Jolanta Marszałek ${ }^{1}$
}

In wheelchair sports, aerobic performance is commonly assessed with the use of an arm crank ergometer (ACE), a wheelchair ergometer (WCE) or a wheelchair treadmill (WCT). There are different protocols to identify peak oxygen uptake in wheelchair sports; however, only a few protocols have been applied to evaluate these conditions in wheelchair basketball players. The purpose of this study was to compare physiological responses during maximal exercise testing with the use of ACE and WCT in wheelchair basketball players. Twelve elite male wheelchair basketball players participated in this study. The research was performed during a training camp of the Polish National Wheelchair Basketball Team. The study participants were divided into two functional categories: A (players with class 1.0 - 2.5) and $B$ (players with class 3.0 - 4.5). Two main maximal exercise tests, i.e. wheelchair treadmill stress test (WCT test) and arm crank ergometer stress test (ACE test) were used to evaluate aerobic performance of the players. There were no statistically significant differences in aerobic tests between the players from both groups. The comparison of results achieved in two aerobic tests performed on WCT and ACE did not reveal any significant differences between the analyzed variables (peak heart rate (HRpeak), peak oxygen uptake (VOzpeak), minute ventilation (VE), anaerobic threshold ( $A T)$, lactate concentration (LApeak), and a drop in lactate concentration (\%LA)). Strong correlations between results achieved in WCT and ACE tests were found for VO2peak, VE and LApeak. The main conclusion of the study is that both WCT and ACE tests may be useful when determining aerobic capacity of wheelchair basketball players. Moreover, both protocols can be used by athletes regardless of their functional capabilities and types of impairment.

Key words: oxygen uptake, wheelchair treadmill, arm cranking, disabled athletes, exercise protocol.

\section{Introduction}

In recent years, the recognition, public interest and participation in Paralympic sports, including wheelchair basketball, have increased remarkably. The volume of literature concerning field-based physiological testing of wheelchair basketball is considerably smaller (Goosey-Tolfrey and Leicht, 2013) compared to able-bodied basketball players (Boone and Bourgois, 2013; Gocentas and Landõr, 2006; Köklü et al., 2011; Pojskić et al., 2015; Žumbakytė-Šermukšnienė et al., 2012). In wheelchair basketball, high-intensity performance and a complex structure of movement are prevalent (Skucas and Pokvytyte, 2017; Yanci et al., 2015). Furthermore, an increase in the number of studies on performance in wheelchair sports has been observed over the past two decades (de Groot et al., 2016; Leicht et al., 2012, 2013; Molik et al., 2010; Paulson and GooseyTolfrey, 2017; Pereira et al., 2016; Vanlandewijck et al., 1999; Weissland et al., 2015). Wheelchair basketball is a team sport for individuals with such chronic conditions resulting in lower-limb

1 - Faculty of Rehabilitation, Jozef Pilsudski University of Physical Education in Warsaw, Poland.

2 - Faculty of Physical Education, Jozef Pilsudski University of Physical Education in Warsaw, Poland. 
disability as spinal cord injury, cerebral palsy, musculoskeletal conditions, spina bifida, amputation and poliomyelitis, and a reduced ability to play running basketball in the same manner as able-bodied players (IWBF, 2014; Paulson and Goosey-Tolfrey, 2017). Thus, wheelchair basketball players use sport-specific manual wheelchairs and are classified according to their physical capacity to perform basic basketball movements (de Groot et al., 2003; IWBF, 2014). Performance in wheelchair basketball is similar to a regular basketball game based upon endurance, strength, speed, coordination and mobility (Cavedon et al., 2015; Iturricastillo et al., 2015; Knechtle and Köpfli, 2001). Therefore, performance testing in wheelchair basketball is complex and difficult. The importance of highlevel aerobic fitness for team sport players is well known (Harrison et al., 2015; Knechtle and Köpfli, 2001). In wheelchair basketball, aerobic power is considered crucial. Aerobic capacity $\left(\mathrm{VO}_{2 \text { peak }}\right)$ is a success-related factor in endurance sports (Pretorius et al., 2015). Lactate concentration (LA $\mathrm{A}_{\text {peak }}$ ) during and after exercising determines the metabolic character of the process and the anaerobic threshold (AT) can be estimated. In practice, LApeak and AT are essential when preparing an appropriate training plan in terms of the type of exercises, repetitions and intensity (intervals between each exercise, a number of sets of exercises) (Ghosh, 2004). Therefore, cardiorespiratory variables as well as LApeak and AT were analyzed in this study.

There are a lot of evaluation protocols used to identify aerobic performance in able-bodied basketball players (Ben Abdelkrim et al., 2010; de Araujo et al., 2014). Although typically the principles of endurance training and aerobic testing are directly transferred from able-bodied sport to disabled sport, it has to be noted that sports performance of wheelchair athletes may be affected by some unique physiological differences (Bhambhani, 2003; de Lira, 2010). Moreover, due to the fact that considerably smaller muscle mass is utilized during upper body exercise (arm cranking) than during lower body exercise, it is often questionable whether the cardiovascular system of wheelchair athletes is fully stressed and maximal values of aerobic power are attained (Bhambhani, 2011). Even though static exercises of upper limbs do not exert a significant influence on the left ventricular function of the heart and on cardiorespiratory adaptation to incremental arm exercises in power lifting athletes (Żebrowska et al., 2013a), it was noted that athletes with left ventricular hypertrophy demonstrated enhanced responses to eccentric arm exercises (Żebrowska et al., 2013b). If lower-limb and upper-limb exercises of similar intensity are performed, the former require greater carbohydrate (muscle glycogen) expenditure and greater lactate production in the exercising limb (Ahlborg and Jensen-Urstad, 1991). Therefore, selecting an optimal exercise protocol is essential for athletes' safety and comfort as well as for obtaining the most interpretable data (Cooper and Storer, 2001). It has been established that in sports testing, an exercise mode should simulate a given motor task as closely as possible (Bhambhani, 2011; Goosey-Tolfrey and Tolfrey, 2008). In wheelchair athletes, aerobic performance is commonly assessed with the use of an arm crank ergometer (ACE), a wheelchair ergometer (WCE) or a wheelchair treadmill (WCT) (Bhambhani, 2011; Cooper and Storer, 2001; Hartung et al., 1993). Although there are many evaluation protocols to identify peak oxygen uptake in wheelchair athletes (Goosey-Tolfrey et al., 2014; Hartung et al., 1993; Leicht et al., 2013; Rasehe et al., 1993; West et al., 2016; Wicks et al., 1983; Veeger et al., 1991), few protocols have been applied to evaluate these conditions specifically in wheelchair basketball players (de Lira et al., 2010; GooseyTolfrey, 2005; Knechtle and Köpfli, 2001; Rotstein et al., 1994). The majority of maximal exercise testing protocols in wheelchair basketball use WCT as the mode of exercise with various combinations of constant and/or increased grade and speed. There is no agreement as to which test protocol yields the most consistent values of peak oxygen uptake in wheelchair basketball players. Hartung et al. (1993) noted that a treadmill protocol involving increments of both speed and grade produced maximal outcomes. Very few studies have been found regarding the use of ACE to determine aerobic performance in wheelchair basketball players. Rotstein et al. (1994) used ACE (Fleish cycle ergometer) to evaluate elite Israeli wheelchair basketball players. The starting load was $30 \mathrm{~W}$, which was increased by $30 \mathrm{~W}$ every 2 minutes. Vanlandewijck et al. (1999) examined 15 wheelchair basketball players and the load in their protocol (power output; PO) increased by $15 \mathrm{~W}$ 
every 3 minutes (with the starting load of $15 \mathrm{~W}$ ). Each athlete was asked to crank with a frequency of around $60 \mathrm{rpm}$. Although it is not a typical arm movement pattern (asymmetrical) for wheelchair basketball, it may be advantageous when practitioners wish to determine physiological capacities of an athlete in isolation from their equipment (Paulson and Goosey-Tolfrey, 2017). Additionally, due to ACE availability in many laboratories and because of low costs and portability of the device (Hutzler, 1998), it could be more applicable for regular aerobic testing performance in wheelchair basketball players. Rotstein et al. (1994) reported low correlations between peak oxygen uptake $\left(\mathrm{VO}_{2 \text { peak }}\right)$ and minute ventilation (VE) which were measured during movement on ACE and WCT $(\mathrm{r}=.57, p=.137$ and $\mathrm{r}$ $=.4, p=.233$, respectively). However, Glaser et al. (1980) and Wicks et al. (1978) reported a high correlation between $\mathrm{VO}_{2 \text { peak, }} \mathrm{VE}$ and peak heart rate (HReak) measured during movements on ACE and WCE. According to the study of Paulsen and Goosey-Tolfrey (2017), ACE is more mechanically efficient than wheelchair propulsion. Higher levels of peak power output ( $\mathrm{PO}_{\text {peak }}$ ) can be obtained on ACE ( $30 \%$ higher), with little difference in $\mathrm{VO}_{2 \text { peak }}$. However, protocols performed on ACE have limited specificity to the type of movement of wheelchair athletes. Still, those protocols may be advantageous when determining physiological capacities of those athletes.

Therefore, the purpose of this study was to compare physiological responses during maximal exercise testing with the use of ACE and WCT in wheelchair basketball players.

\section{Methods}

\section{Participants}

Twelve elite male wheelchair basketball players (mean age $28.2 \pm 7.1$ years) volunteered to participate in the study. They were informed about the purpose and all testing procedures, and were asked to sign the consent form. All the procedures were approved by the local bioethics committee and were completed in accordance with ethical standards as described in the Declaration of Helsinki. The research was carried out in April 2017 during a training camp of the Polish National Wheelchair Basketball Team. The subjects were divided into functional classes (from 1.0 to 4.5 ) according to the International
Wheelchair Basketball Federation (IWBF) procedures (IWBF, 2014). All the players were evaluated by international classifiers. The characteristics of the study participants are presented in Table 1.

Additionally, the subjects were divided into two functional categories: A (players with class $1.0-2.5 ; n=5$ ) and B (players with class $3.0-$ $4.5 ; \mathrm{n}=7$ ). There were no statistically significant differences in anthropometric variables between players (except for vertical reach in a seated position).

\section{Experimental procedures and measures}

A personal data form was completed by all the participants. Prior to the main tests conducted in laboratory settings, anthropometric measurements were made and personal data were collected (age, body mass, body height, vertical reach in a seated position, arm span, and type of impairment). Body mass was evaluated using a medical scale. Body height was measured in a lying position on a mattress with the GPM anthropometer. Vertical reach in a seated position and arm span were measured in a sitting position (in a wheelchair) near the wall with the use of a measuring tape. Each athlete was asked to raise his dominant hand vertically to the highest attainable position on the wall without lifting the buttocks. The maximum vertical distance from the floor to the highest fingertip (when the hand was raised vertically to the highest attainable position) was recorded. The measurement error in each trial was $\pm .5 \mathrm{~kg}, \pm .5 \mathrm{~cm}$ and $\pm .5 \mathrm{~cm}$, respectively.

Two maximal exercise tests, i.e. wheelchair treadmill stress test (WCT test) and arm crank ergometer stress test (ACE test) were used to evaluate aerobic performance of elite male wheelchair basketball players (Table 3). The WCT test was performed on the WCT HP Cosmos Saturn. The participants used their sports wheelchairs. The sports wheelchair was connected to the metal frame for security. The speed and grade of the treadmill were increased simultaneously. The test started at $3.2 \mathrm{~km} / \mathrm{h}$ and $0 \%$ WCT grade. The speed and grade of the treadmill were increased every two minutes (0-2 $\mathrm{min}: 3.2$ $\mathrm{km} / \mathrm{h}, 0 \%$; $2-4 \mathrm{~min}: 4.8 \mathrm{~km} / \mathrm{h}, 1.0 \%$; $4-6 \min : 6.4$ $\mathrm{km} / \mathrm{h}, 1.5 \%$; 6-8 $\min : 8 \mathrm{~km} / \mathrm{h}, 2.0 \%$; $8-10 \mathrm{~min}: 9.6$ $\mathrm{km} / \mathrm{h}, 2.5 \% ; 10-12 \mathrm{~min}: 11.2 \mathrm{~km} / \mathrm{h}, 3.0 \%)$. The distance covered in the WCT test was registered for further analysis (Hartung et al., 1993). 
The ACE test was performed on the ACE Lode (Groningen). To maximize trunk stability, the players used their own basketball wheelchairs and strapping systems as appropriate. ACE was firmly affixed to a wall-mounted gymnastic ladder. The ergometer rotation axis was set so that it was level with the subject's glenohumeral joints. Two assistants stabilized the wheelchair to help minimize rotational movements during arm cranking. The breaking force in this test was increased constantly by $35 \mathrm{~W}$ every two minutes (with the starting load of $35 \mathrm{~W}$ ). The players were asked to maintain cranking speed at $70 \mathrm{rpm}$.

In the WCT and ACE tests, the following physiological variables were measured: peak heart rate ( $\left.\mathrm{HR}_{\text {peak }}\right)$, peak oxygen uptake $\left(\mathrm{VO}_{2 \text { peak }}\right)$, minute ventilation (VE), anaerobic threshold (AT). The measurements were made using the $\mathrm{K} 5$ system (Cosmed, Italy) that consists of a mask and a portable unit worn by the participant. Breath-bybreath data were averaged over $15 \mathrm{~s}$. The heart rate (HR) was monitored with a GARMIN sensor connected and compatible with K5. HRpeak was the highest value in the conducted tests, while $\mathrm{VO}_{2 \text { peak }}$ was the highest value obtained over $15 \mathrm{~s}$. The AT was measured with the use of the modified V-slope method (Beaver et al., 1986). This modification concerned the method of obtaining AT results based on the lactate curve (a graphical method; the AT result was the intersection of the straight line (the load) and the curve (LA)). Lactate concentration (LApeak) and a drop in lactate concentration (\%LA) were measured prior to performing WCT and ACE tests, during the tests (every 2 minutes), immediately after the tests and in the 3rd, 6th, 9th and 30th minute of recovery. The difference between LApeak and LA in the 30th minute of recovery was calculated to assess the ability to utilize lactate (a drop in lactate concentration - \%LA). Moreover, the distance covered during the WCT test was measured.

\begin{tabular}{|c|c|c|c|c|c|c|c|c|}
\hline \multicolumn{9}{|c|}{$\begin{array}{c}\text { Table } \mathbf{1} \\
\text { Physical impairment and anthropometric characteristics of elite wheelchair basketball athletes }\end{array}$} \\
\hline Subject & $\begin{array}{l}\text { Age } \\
\text { [years] }\end{array}$ & $\begin{array}{l}\text { Body } \\
\text { mass }[\mathrm{kg}]\end{array}$ & $\begin{array}{l}\text { Body } \\
\text { height }[\mathrm{cm}]\end{array}$ & $\begin{array}{l}\text { Vertical } \\
\text { reach in a } \\
\text { seated } \\
\text { position } \\
{[\mathrm{cm}]}\end{array}$ & Arm span $[\mathrm{cm}]$ & $\begin{array}{l}\text { Type of } \\
\text { impairment }\end{array}$ & $\begin{array}{l}\text { Functional level } \\
\text { - class } \\
\text { (1-4.5 CLASS) }\end{array}$ & $\begin{array}{l}\text { Category } \\
\text { (A-B) }\end{array}$ \\
\hline 1 & 27 & 77.1 & 185 & 185.2 & 194.2 & PARAPLEGIA & 1 & A \\
\hline 2 & 25 & 60.1 & 176 & 201 & 181.5 & AMPUTATION & 4 & B \\
\hline 3 & 36 & 61.6 & 173 & 178 & 177.3 & PARAPLEGIA & 1 & A \\
\hline 4 & 33 & 75.6 & 185 & 185 & 197 & PARAPLEGIA & 1 & A \\
\hline 5 & 30 & 61.9 & 162 & 200 & 179 & OTHER & 4 & B \\
\hline 6 & 17 & 72.9 & 197 & 213 & 201 & OTHER & 4.5 & B \\
\hline 7 & 33 & 76.3 & 183 & 215 & 184 & AMPUTATION & & B \\
\hline 8 & 16 & 41 & 154 & 160 & 164.3 & PARAPLEGIA & 1 & A \\
\hline 9 & 33 & 77.8 & 184 & 187 & 183.3 & PARAPLEGIA & 1.5 & A \\
\hline 10 & 30 & 80.8 & 180 & 210 & 187 & OTHER & 3 & B \\
\hline 11 & 37 & 65.2 & 176 & 196 & 179.3 & OTHER & 4 & B \\
\hline 12 & 21 & 58.3 & 165 & 186 & 170.5 & SPINA BIFIDA & 3 & B \\
\hline mean & 28.2 & 67.4 & 176.7 & 193.0 & 183.2 & & & \\
\hline sd & 7.1 & 11.5 & 11.8 & 16.0 & 10.6 & & & \\
\hline & & & & & sd-standard devi & iation & & \\
\hline
\end{tabular}


Table 2

Anthropometric characteristics of elite wheelchair basketball players divided into two functional categories

\begin{tabular}{|c|c|c|c|c|c|c|}
\hline \multicolumn{2}{|c|}{$\begin{array}{l}\text { Category } \\
(\mathrm{A}-\mathrm{B})\end{array}$} & \multirow{2}{*}{$\begin{array}{l}\text { Age } \\
\text { [years] } \\
29.0\end{array}$} & \multicolumn{4}{|c|}{\begin{tabular}{l}
\multicolumn{4}{c}{ Vertical } \\
Body mass Body height reach in a \\
$\begin{array}{lll}{[\mathrm{kg}]} & \text { seated } \\
& {[\mathrm{cm}]} & \text { position }[\mathrm{cm}]\end{array}$
\end{tabular}} \\
\hline \multirow{2}{*}{$\begin{array}{l}A \\
(n=5)\end{array}$} & mean 29.0 & & 66.6 & 176.2 & 179.0 & 183.2 \\
\hline & $\mathrm{sd}$ & 8.0 & 15.8 & 13.4 & 11.2 & 13.3 \\
\hline \multirow{2}{*}{$\begin{array}{l}B \\
(n=7)\end{array}$} & me & 27.6 & 67.9 & 177.0 & 203.0 & 183.2 \\
\hline & $\mathrm{sd}$ & 7.0 & 8.7 & 11.7 & 10.4 & 9.4 \\
\hline$p$ & & n.s. & n.s. & n.s. & .005 & n.s. \\
\hline
\end{tabular}

sd-standard deviation; $p<.05$

Table 3

Load progression in the wheelchair treadmill stress test (WCT test) and arm crank ergometer stress test (ACE test).

\begin{tabular}{llllll} 
& & \multicolumn{3}{l}{ ACE test $[\mathrm{km} / \mathrm{h}]$} \\
\cline { 3 - 6 } Stage & Time [min] & Speed $[\mathrm{km} / \mathrm{h}]$ & Slope $[\%]$ & Speed $[\mathrm{rpm}]$ & Load [Watt] \\
\hline 1 & $0-2$ & 3.2 & 0 & 70 & 35 \\
2 & $2-4$ & 4.8 & 1.0 & 70 & 70 \\
3 & $4-6$ & 4.6 & 1.5 & 70 & 105 \\
4 & $6-8$ & 8.0 & 2.0 & 70 & 140 \\
5 & $8-10$ & 9.6 & 2.5 & 70 & 175 \\
6 & $10-12$ & 11.2 & 3.0 & 70 & 210 \\
\hline
\end{tabular}

Table 4

Comparison of results achieved by wheelchair basketball players representing functional categories $A$ and $B$ in the wheelchair treadmill stress test

\begin{tabular}{|c|c|c|c|c|c|c|c|}
\hline $\begin{array}{l}\text { Category } \\
\text { (A-B) }\end{array}$ & $\begin{array}{l}\mathrm{HR}_{\text {peak }} \\
\text { [beat/min] }\end{array}$ & $\begin{array}{l}\text { VEpeak } \\
{[1 / \mathrm{min}]}\end{array}$ & $\begin{array}{l}\mathrm{VO}_{2 \text { peak }} \\
{[\mathrm{ml} / \mathrm{kg} / \mathrm{min}]}\end{array}$ & $\begin{array}{l}\mathrm{AT} \\
{[\text { beat } / \mathrm{min}]}\end{array}$ & $\begin{array}{l}\text { Distance } \\
{[\mathrm{m}]}\end{array}$ & $\begin{array}{l}\text { LA peak } \\
{[\mathrm{mmol} / \mathrm{L}]}\end{array}$ & $\%$ LA [\%] \\
\hline $\begin{array}{l}A \\
(n=5)\end{array}$ & 188.8 & 111.0 & 42.2 & 161.4 & 1039.2 & 11.8 & 55.4 \\
\hline$(n=5)$ & 6.8 & 35.2 & 5.4 & 6.5 & 88.1 & 2.4 & 5.4 \\
\hline mean & 196.1 & 144.4 & 47.7 & 171.4 & 1146.7 & 12.1 & 50.5 \\
\hline \multicolumn{8}{|l|}{$B(n=7)$} \\
\hline sd & 7.8 & 38.6 & 5.1 & 14.9 & 170.9 & 1.8 & 2.3 \\
\hline$p$ & n.s. & n.s. & n.s. & n.s. & n.s. & n.s. & n.s. \\
\hline
\end{tabular}

$s d-$ standard deviation; $p<.05$

$\% L A[\%]-$ drop in lactate concentration in $\%$ 


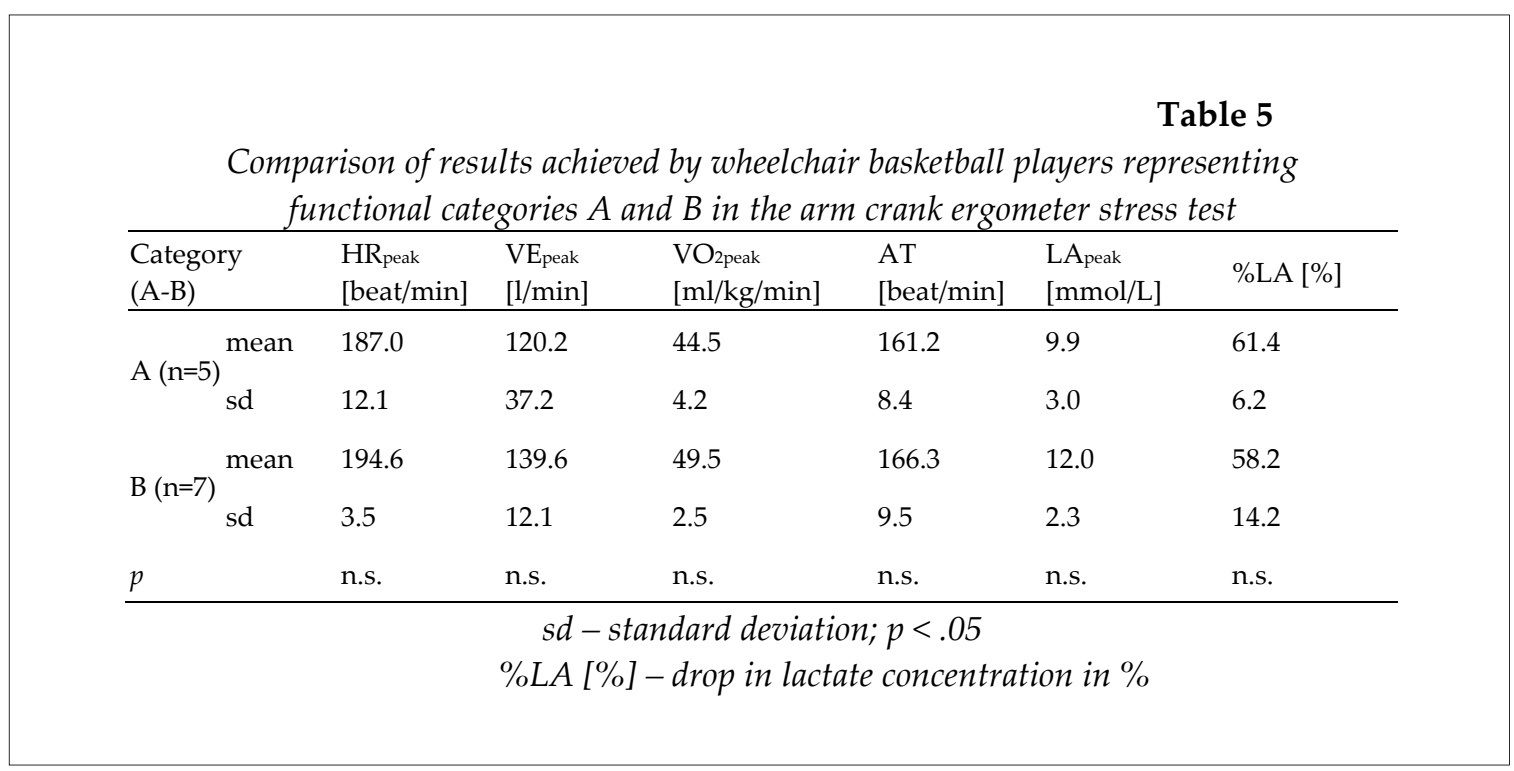

\begin{tabular}{|c|c|c|c|c|c|c|}
\hline \multicolumn{7}{|c|}{$\begin{array}{c}\text { Table } 6 \\
\text { Comparison of results achieved in two aerobic tests performed } \\
\text { on the wheelchair treadmill and the arm crank ergometer }\end{array}$} \\
\hline Measuring equipment & $\begin{array}{c}\mathrm{HR}_{\text {peak }} \\
\text { [beat } / \mathrm{min}]\end{array}$ & $\begin{array}{l}\text { VEpeak } \\
{[1 / \mathrm{min}]}\end{array}$ & $\begin{array}{c}\mathrm{VO}_{2 \text { peak }} \\
{[\mathrm{ml} / \mathrm{kg} / \mathrm{min}]}\end{array}$ & $\begin{array}{c}\text { AT } \\
\text { [beat } / \mathrm{min}]\end{array}$ & $\begin{array}{c}\text { LApeak } \\
{[\mathrm{mmol} / \mathrm{L}]}\end{array}$ & $\%$ LA [\%] \\
\hline \multirow{4}{*}{$\begin{array}{l}\text { Wheelchair } \\
\text { treadmill } \\
\text { (WCT) } \\
\text { Arm crank } \\
\text { ergometer } \\
\text { (ACE) }\end{array}$} & 193.1 & 130.5 & 45.4 & 167.3 & 12.0 & 52.7 \\
\hline & 8.0 & 39.5 & 5.7 & 12.8 & 2.0 & 4.6 \\
\hline & 191.4 & 131.5 & 47.4 & 164.2 & 11.1 & 59.5 \\
\hline & 8.7 & 26.1 & 4.1 & 9.0 & 2.7 & 11.2 \\
\hline$p$ & n.s. & n.s. & n.s. & n.s. & n.s. & n.s \\
\hline \multicolumn{7}{|c|}{$\begin{array}{c}s d-\text { standard deviation; } p<.05 \\
\% L A[\%]-\text { drop in lactate concentration in } \%\end{array}$} \\
\hline
\end{tabular}

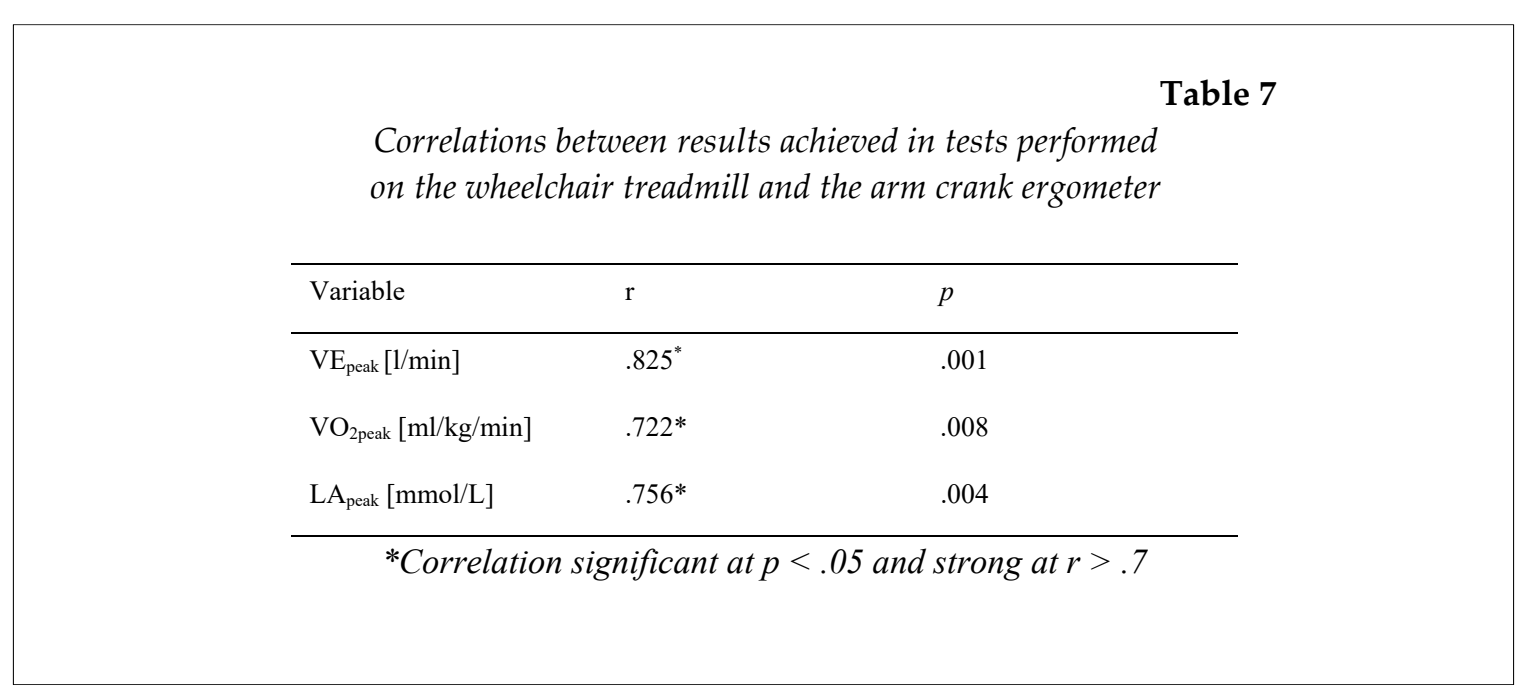




\section{Statistical Analysis}

All calculations and analyses were performed using the SPSS IBM Statistics 24 for Windows. The analysis of the quantitative data was based on arithmetic means and standard deviations $(s d)$. The Kolmogorov-Smirnov test was applied in order to examine the distribution of results.

Results between players representing functional categories A and B were compared with the t-test for independent samples. The level of significance was set at $p<.05$. The t-test for dependent samples was used to compare results achieved in both physiological tests (WCT and ACE tests). The level of significance was set at $p<$ .05 .

In order to determine the relationship between the indicators for aerobic performance, the Pearson correlation analysis was performed. The correlation was significant at $p<.05$ and strong at $\mathrm{r}>$.7.

\section{Results}

The comparisons of results achieved by wheelchair basketball players representing functional categories A and B in both tests (WCT and ACE tests) are presented in Tables 4 and 5. No statistically significant differences were revealed between the players.

The comparison of results achieved in the two aerobic tests did not show any significant differences between the analyzed variables, i.e. $\mathrm{HR}_{\text {peak, }} \mathrm{VO}_{2 \text { peak, }} \mathrm{VE}, \mathrm{AT}, \mathrm{LA}_{\text {peak }}$ and \%LA (Table 6).

Strong correlations $(r>.7)$ were observed between results achieved in WCT and ACE tests (Table 7). Correlations were confirmed between three variables, i.e. $\mathrm{VO}_{2 \text { peak, }} \mathrm{VE}$ and $\mathrm{LA}_{\text {peak }}(\mathrm{r}=.825$, $\mathrm{r}=.722$, and $\mathrm{r}=.756$, respectively).

\section{Discussion}

The purpose of this study was to compare physiological responses during maximal exercise testing with the use of ACE and WCT in wheelchair basketball players. The main conclusion of this study is that there is no significant difference between the two approaches to assess aerobic capacity ( $\left.\mathrm{VO}_{2 \text { peak }}\right)$. It could be suggested that both methods are not analogous, yet they may be equally useful when determining $\mathrm{VO}_{2 \text { peak }}$ in wheelchair basketball players (Tørhaug et al., 2016). $\mathrm{VO}_{\text {2peak }}$ values are similar but muscles that are involved in movement performance during both tests on various devices (ACE and WCT) are different because of movement specificity (Akınoğlu and Kocahan, 2017; Morrow et al., 2009; Paulsen and Goosey-Tolfrey, 2017; Rankin et al., 2011).

The results confirmed that both testing protocol performed on two different types of equipment (WCT and ACE) can be used for aerobic capacity assessment of wheelchair basketball athletes. There are some advantages and disadvantages of both protocols. The test conducted on WCT corresponds to the work performed by players while wheeling during the match (Bernardi et al., 2010; Goosey-Tolfrey and Leicht, 2013; Hartung et al., 1993). Moreover, the wheeling technique affects the test performance. In other words, differences in trunk stabilization or other functional abilities between players can exert a considerable influence on the level of parameters obtained during the test. Moreover, the type or quality of wheelchairs used by players as well as the type of strapping, belts or stabilization may determine WCT test performance.

During the WCT test, the treadmill grade and speed were increased every two minutes. That protocol seems to be more effective than those that involve increasing the grade or speed separately (Hartung et al., 1993). Still, that protocol seems to be more difficult due to problems with trunk stabilization in the last stages of the test. Moreover, a treadmill slope is not a natural condition when it comes to wheelchair basketball.

The test performed on ACE gives the opportunity to reduce the impact of the propulsion technique and differences between trunk stabilization on aerobic capacity (Tropp et al., 1997). However, the work done on ACE is not strongly related to performance during a wheelchair basketball match (Tropp et al., 1997). Another advantage of using ACE is that it can be easily transported to wheelchair basketball camps or training sessions. It is also worth noting that natural conditions of propulsion (symmetrical movement) on the treadmill could increase the advantage of this testing solution. On the other hand, in the treadmill protocol, speed as well as the angle of treadmill inclination were increased simultaneously and gradually. The increasing treadmill inclination during the test could affect trunk stability and the test results. In the ACE test, there were no disturbing factors. The advantages 
and disadvantages of both tests performed on two different types of equipment showed that coaches can choose the right test in order to meet their needs and achieve their training goals.

The duration of tests was similar in both protocols. The players performed both tests in 8 to 12 minutes, which allowed for proper analysis of aerobic performance variables. In both test protocols, the loads were increased every 2 minutes, what allowed for a comparison of variables in both test protocols was easier (LA concentration, $\mathrm{HR}_{\text {peak }}$ and $\mathrm{VO}_{2 \text { peak }}$ ).

Aerobic capacity $\left(\mathrm{VO}_{2 \max }\right)$ of able-bodied individuals is limited by cardiac output (Tørhaug et al., 2016). Tørhaug et al. (2016) indicated that it was not the load applied in a test, but the weakness of aerobic capacity of small muscle groups involved in the movement that limited the athletes in the ACE test (Di Blasio et al., 2009; Tørhaug et al., 2016). It seems likely that training these muscle groups prior to the test would be a good solution regarding aerobic capacity assessment in disabled athletes.

The present study revealed higher values of $\mathrm{HR}_{\text {peak }}$ and LA as well as lower values of $\mathrm{VO}_{2 \text { peak }}$ during the test on the treadmill compared to the arm crank test. It seems that wheeling, which is an everyday activity for most players, is a motor task that is similar to moving on a wheelchair on the treadmill. Wheelchair users are more familiar with this task than with arm cranking. However, in order to be able to compare aerobic capacity results from both tests objectively, it is necessary to calculate energy cost. Even though energy cost of movement is calculated, there are still some factors influencing or limiting players' movement in each test. Therefore, it appears that the results obtained in the ACE test and the treadmill test can be compared. This idea was also introduced by Tørhaug et al. (2016), who added that the results were not comparable especially for submaximal levels of energy cost.

The findings of the present study were compared with the results of Swiss players (Knechtle and Kopøi, 2001). Mean $\mathrm{VO}_{2 \text { peak }}$ values from the treadmill test of the Polish national players were higher than those of the Swiss players ( $\mathrm{VO}_{\text {2peak }} 45.4$ vs. $35.1 \mathrm{ml} / \mathrm{kg} / \mathrm{min}$, stress test on the treadmill) (Knechtle and Kopøi, 2001). No studies have been found regarding the assessment of physiological responses during maximal exercise testing with the use of ACE in wheelchair basketball teams. Therefore, the greatest achievement of this study is the indication of the possibility of using two test protocols interchangeably. Wheelchair basketball coaches may use not only the WCT but also the ACE test (Hutzler, 1998). Haisma et al. (2006) compared $\mathrm{VO}_{2 \text { peak }}$ results from a wheelchair ergometer and ACE tests obtained by people with spinal cord injury and they noted higher $\mathrm{VO}_{2 \text { peak }}$ values in the WCT test (Haisma et al., 2006). This difference could stem from population heterogeneity, i.e. inherent $\mathrm{VO}_{\text {2peak }}$ levels of the study population (Tørhaug et al., 2016). On the other hand, Hintzy et al. (2002) reported higher levels of $\mathrm{PO}_{\text {peak }}$ during the movement on the ACE ( $30 \%$ higher) with similar values of $\mathrm{VO}_{2 \text { peak. }}$.

Muscle fatigue could be observed when lactate production in blood exceeded its elimination and reached the anaerobic threshold (Ghosh, 20074; Schneider et al., 1999). In our study, LApeak values were slightly lower in the ACE. It indicated that LA accumulation in blood was slower in the ACE test. It may have been brought about by the specificity of the task that differentiated between the work of the upper body on both devices (Di Blasio et al., 2009).

The fact that no differences were revealed regarding results achieved by players of different functional classes confirms that both protocols can be used for players of all classes. These findings seem to be crucial when testing wheelchair basketball players, as they can be compared regardless of their functional capabilities and types of impairment.

Both the ACE and the treadmill tests lasted between 8 and 12 minutes, which was in line with Perret and Abel's (2016) recommendations. Due to different types of functional abilities of the examined wheelchair basketball players, the proposed test protocols seem to have been selected properly.

The limitation of the study was a small sample size of elite male wheelchair basketball players. We recommend that in future studies, the analysis should be divided into all eight functional classes. On the practical side, it seems important to search for non-laboratory (field-based) tests to assess the level of aerobic capacity of wheelchair basketball players. The application of such tests can be very helpful in coaching wheelchair 
basketball teams at each level. Therefore, there is a need to seek appropriate training methods that would improve aerobic capacity of wheelchair basketball players.
The main conclusion of the study is that both WCT and ACE tests may be useful when determining aerobic capacity of wheelchair basketball players. Moreover, both protocols can be used by athletes regardless of their functional capabilities and types of impairment.

\section{Acknowledgments}

The authors would like to thank the players and coaches from the Polish National Wheelchair Basketball Team for their participation in the study. The study has been supported by the grant from the Academic Sport Research from the Polish Ministry of Higher Education and Science (PB-87; N RSA4 01854) and funds for science of the Polish Ministry of Higher Education and Science in the years 2016-2018 ("Academic Sport Development" program); grant no N RSA4 01854 (“Optimization of controlling physical fitness of wheelchair basketball players").

\section{References}

Ahlborg G, Jensen-Urstad M. Metabolism in exercising arm vs. leg muscle. Clin Physiol, 1991; 11(5): 459-68

Akınoğlu B, Kocahan T. Characteristics of upper extremity's muscle strength in Turkish national wheelchair basketball players team. J Exerc Rehabil, 2017; 13(1): 62-67

Ben Abdelkrim N, Castagna C, Jabri I, Battikh T, El Fazaa S, El Ati J. Activity profile and physiological requirements of junior elite basketball players in relation to aerobic-anaerobic fitness. J Strength Cond Res, 2010; 24(9): 2330-2342

Bernardi M, Guerra E, Di Giacinto B, Di Cesare A, Castellano V, Bhambhani Y. Field evaluation of paralympic athletes in selected sports: implications for training. Med Sci Sports Exerc, 2010; 42(6): 1200-1208

Bhambhani Y. Principles of Fitness Assessment and Training for Wheelchair Athletes. In: Steadward RD, Wheeler GD, Watkinson EJ (Eds.), Adapted Physical Activity. The University of Alberta Press and The Steadward Centre, 511-539; 2003

Bhambhani Y. Physiology. In: Vanlandewijck Y, Thompson W (Eds.), The Paralympic athlete. Handbook of Sports Medicine and Science. Wiley-Blackwell, 51-73; 2011

Boone J, Bourgois J. Morphological and Physiological Profile of Elite Basketball Players in Belgium. Int J Sport Physiol, 2013; 8: 630-638

Cavedon V, Zancanaro C, Milanese C. Physique and Performance of Young Wheelchair Basketball Players in Relation with Classification. PLoS ONE, 2015; 10, 11: e0143621. https://doi.org/10.1371/journal.pone.0143621

Cooper CB, Storer TW. Exercise testing and interpretation. A practical approach. United Kingdom at the University Press, Cambridge, 78-83; 2001

de Araujo GG, Manchado-Gobatto Fde B, Camargo BHF, Gobatto CA. Anaerobic and Aerobic Performances in Elite Basketball Players. J Hum Kinet, 2014; 42: 137-147

de Groot S, Gervais P, Coppoolse JM, Natho K, Bhambhani Y, Steadward R, Wheeler GD. Evaluation of a new basketball wheelchair design. Tech and Disabil, 2003; 15(1): 7-18

de Lira CAB, Vancini RL, Minozzo FC, Sousa BS, Dubas JP, Andrade MS, Steinberg LL, da Silva AC. Relationship between aerobic and anaerobic parameters and functional classification in wheelchair basketball players. Scand J Med Sci Sports, 2010; 8(20): 638-643

Di Blasio A, Sablone A, Civino P, D'Angelo E, Gallina S, Ripari P. Arm vs. Combined Leg and Arm Exercise: Blood Pressure Responses and Ratings of Perceived Exertion at the Same Indirectly Determined Heart 
Rate. J Sports Sci Med, 2009; 8(3): 401-409

Glaser RM, Sawka MN, Brune MF, Wilde SW. Physiological responses to maximal effort wheelchair and arm crank ergometry. J Appl Phyiol: Respirat Environ Exer Physiol, 1980; 48(6): 1060-1064

Gocentas A, Landõr A. Dynamic sport-specific testing and aerobic capacity in top level basketball players. Papers on Anthropology, 2006; 15: 55-63

Goosey-Tolfrey VL. Physiological profiles of elite wheelchair basketball players in preparation for the 2000 Paralympic Games. Adapt Phys Act Quart, 2005; 22: 57-66

Goosey-Tolfrey VL, Leicht C. Field-Based Physiological Testing of Wheelchair Athletes. Sports Med, 2013; 43(2): 77-91

Goosey-Tolfrey VL, Paulson TA, Tolfrey K, Eston RG. Prediction of peak oxygen uptake from differentiated ratings of perceived exertion during wheelchair propulsion in trained wheelchair sportspersons. Eur J Appl Physiol, 2014; 114(6): 1251-1258

Goosey-Tolfrey VL, Tolfrey K. The multi-stage fitness test as a predictor of endurance fitness in wheelchair athletes. J Sports Sci, 2008; 26(5): 511-517

Ghosh AK. Anaerobic Threshold: Its Concept and Role in Endurance Sport. Malays J Med Sci, 2004; 11(1): 2436

Haisma JA, van der Woude LHV, Stam HJ, Bergen MP, Sluis TAR, Bussmann JBJ. Physical capacity in wheelchair-dependent persons with a spinal cord injury: a critical review of the literature. Spinal Cord, 2006; 44(11): 642-652

Harrison CB, Gill ND, Kinugasa T, Kilding AE. Development of Aerobic Fitness in Young Team Sport Athletes. Sports Med, 2015; 45(7): 969-983

Hartung GH, Lally DA, Blancq RJ. Comparison of treadmill exercise testing protocols for wheelchair users. Eur J Appl Physiol, 1993; 66: 362-365

Hintzy F, Tordi N, Perrey S. Muscular efficiency during arm cranking and wheelchair exercise: a comparison. Int J Sports Med, 2002, 23(6): 408-414

Hutzler Y. Anaerobic fitness testing of wheelchair users. Sports Med, 1998; 25(2): 101-113

Iturricastillo A, Granados C, Yanci J. Changes in Body Composition and Physical Performance in Wheelchair Basketball Players During a Competitive Season. J Hum Kinet, 2015; 10: 157-165

IWBF. International wheelchair basketball federation official player classification manual. Winnipeg, Canada; 2014

Knechtle B, Köpfli W. Treadmill exercise testing with increasing inclination as exercise protocol for wheelchair athletes. Spinal Cord, 2001; 39: 633-636

Köklü Y, Alemdaroğlu U, Koçak FU, Erol AE, Fındıkoğlu G. Comparison of Chosen Physical Fitness Characteristics of Turkish Professional Basketball Players by Division and Playing Position. J Hum Kinet, 2011; 10(30): 99-106

Leicht CA, Bishop NC, Goosey-Tolfrey VL. Submaximal exercise responses in tetraplegic, paraplegic and nonspinal cord injured elite wheelchair athletes. Scand J Med Sci Sports, 2012; 22(6): 729-736

Leicht CA, Tolfrey K, Lenton JP, Bishop NC, Goosey-Tolfrey VL. The verification phase and reliability of physiological parameters in peak testing of elite wheelchair athletes, Eur J Appl Physiol, 2013; 113(2): 337345

Molik B, Kosmol A, Laskin JJ, Skucas K, Bida U. Relationship between Functional Classification Levels and Anaerobic Performance of Wheelchair Basketball Players. Res Q Exerc Sport, 2010; 81(1): 69-73

Morrow MM, Hurd WJ, Kaufman KR, An KN. Upper-limb joint kinetics expression during wheelchair propulsion. J Rehabil Res Dev, 2009; 46(7): 939-944

Paulson T, Goosey-Tolfrey V. Current perspectives on profiling and enhancing wheelchair court-sport performance. Int J Sports Physiol Perform, 2017; 12(3): 275-283 
Pereira RN, Abreu MFR, Gonçalves CB, Corrêa WFS, Mizuhira DR, Moreno MA. Respiratory muscle strength and aerobic performance of wheelchair basketball players. Motriz: Revista de Educação Física, 2016; 22(3): 124-132

Perret C, Abel T. Physiology. In: Vanlandewijck Y., Thompson W. (Eds), Training and coaching the paralympic athlete. Handbook of Sports Medicine and Science. Wiley-Blackwell, 53-74; 2016

Pojskić H, Šeparović V, Užičanin E, Muratović M, Mačković S. Positional Role Differences in the Aerobic and Anaerobic Power of Elite Basketball Players. J Hum Kinet, 2015; 49: 219-227

Pretorius J, Pieterse J, Toriola AL, Kubayi NA, Aerobic Fitness of South African Wheelchair Basketball and Rugby Players. Biomed Res, 2015; 26(2): 249-253

Price DT, Davidoff R, Balady GJ. Comparison of cardiovascular adaptations to long-term arm and leg exercise in wheelchair athletes versus long-distance runners. Am J Cardiol, 2000; 85: 996-1001

Rankin JW, Richter WM, Neptune RR. Individual muscle contributions to push and recovery subtasks during wheelchair propulsion. J Biomech, 2011; 44(7): 1246-1252

Rasche W, Janssen TWJ, VanOers CAJM, Hollander AP, van der Woode LHV. Responses of subjects with spinal cord injuries to maximal wheelchair exercise: comparison of continuous and discontinuous protocols. Eur J Appl Physiol, 1993; 66: 328-331

Rotstein A, Sagiv M, Ben-Sira D, Werber G, Hutzler J, Annenburg H. Aerobic capacity and anaerobic threshold of wheelchair basketball players. Paraplegia, 1994; 32(3): 196-201

Tropp H, Samuelsson K, Jorfeldt L. Power output for wheelchair driving on a treadmill compared with arm crank ergometry. Br J Sports Med, 1997; 31(1): 41-44

Schneider DA, Sedlock DA, Gass E, Gass G. VO2 peak and the gas-exchange anaerobic threshold during incremental arm cranking in able-bodied and paraplegic men. Eur J Appl Physiol Occup Physiol, 1999; 80(4): 292-297

Skucas K, Pokvytyte V. Short-term moderate intensive high volume training program provides aerobic endurance benefit in wheelchair basketball players. J Sports Med Phys Fitness, 2017; 57(4): 338-344

Tørhaug T, Brurok B, Hoff J, Helgerud J, Leivseth G. Arm Crank and Wheelchair Ergometry Produce Similar Peak Oxygen Uptake but Different Work Economy Values in Individuals with Spinal Cord Injury. BioMed Res Int, 2016; 1-7

Veeger HEJ, Yahmed MH, van der Woude LHV, Charpentier P. Peak oxygen uptake and maximal power output of Olympic wheelchair-dependent athletes. Med Sci Sports Exerc, 1991; 23: 1201-1209

Vanlandewijck YC, Daly DJ, Theisen DM. Field test evaluation of aerobic, anaerobic, and wheelchair basketball skill performances. Int J Sports Med, 1999; 20(8): 548-54

Weissland T, Faupin A, Borel B, Berthoi S, Lepretre P-M. Effects of modified multi-stage field test on performance and physiological responses in wheelchair basketball players. BioMed Res Int, 2015; 2(24): 1-7

West CR, Leicht CA, Goosey-Tolfrey VL, Romer LM. Perspective: Does Laboratory-Based Maximal Incremental Exercise Testing Elicit Maximum Physiological Responses in Highly-Trained Athletes with Cervical Spinal Cord Injury? Front Physiol, 2016; 6: 419

Wicks JR, Lymburner K, Dinsdale SM, Jones NL. The use of multistage exercise testing with wheelchair ergometry and arm cranking in subjects with spinal cord lesions. Paraplegia, 1977; 15(3): 252-261

Wicks JB, Oldridge NB, Cameron RJ, Jones NL. Arm-cranking and wheelchair ergometry in elite spinal cord athletes. Med Sci Sports Exerc, 1983; 15: 224-231

Yanci J, Granados C, Otero M, Badiola A, Olasagasti J, Bidaurrazaga-Letona I, Iturricastillo A, Gil SM. Sprint, agility, strength and endurance capacity in wheelchair basketball players. Biol Sport, 2015; 32(1): 71-78 
Žumbakytė-Šermukšnienė R, Kajënienė A, Berškienė K, Daunoravičienė A, Sederevičiūtè-Kandratavičienė R. Assessment of the effect of anthropometric data on the alterations of cardiovascular parameters in Lithuanian elite male basketball players during physical load. Medicina (Kaunas), 2012; 48(11): 566-71

Żebrowska A, Gąsior Z, Jastrzębski D. Cardiovascular effects of Valsalva maneuver during static arm exercise in elite power lifting athletes. Adv Exp Med Biol, 2013a; 755: 335-342

Żebrowska A, Waśkiewicz Z, Zając A, Gąsior Z, Galbo H, Langfort J. IGF-1 response to arm exercise with eccentric and concentric muscle contractions in resistance-trained athletes with left ventricular hypertrophy. Int J Sports Med, 2013b; 34: 116-122

\section{Corresponding author:}

\section{Jolanta Marszałek}

Faculty of Rehabilitation

Jozef Pilsudski University of Physical Education in Warsaw

ul. Marymoncka 34, 00-968 Warsaw, Poland

Telephone: +4883404 31, wew. 340

Fax: +48 228354798

E-mail: marszalek.jolanta@gmail.com 